\section{Necessidades de saúde pela voz da sociedade civil e do Estado}

\author{
Health needs according to civil \\ society and the state
}

\author{
1 Escola de Enfermagem, \\ Universidade de São Paulo, \\ São Paulo, Brasil. \\ 2 Escola de Enfermagem \\ de Ribeirão Preto, \\ Universidade de São Paulo, \\ Ribeirão Preto, Brasil. \\ Correspondência \\ C. M. S. Campos \\ Departamento de \\ Enfermagem em Saúde \\ Coletiva, Escola \\ de Enfermagem \\ Universidade de São Paulo. \\ Av. Dr. Enéas de Carvalho \\ Aguiar 419, São Paulo, SP \\ 15403-000, Brasil. \\ celiasiv@usp.br
}

\begin{abstract}
This study focused on the health needs of a population covered by a primary healthcare center (PHC) in the city of São Paulo, Brazil. The overall objective was to investigate the perceived health needs as the object of health work. The study thus identified and analyzed what residents recognize as health needs, as well as what the PHC workers grasp as the object. The PHC workers and local residents were the research subjects. A semi-structured interview was used for data collection and thematic analysis for grasping the reality. The empirical categories identified were: need for state presence, social reproduction needs, and need for political participation recognized by local residents as health needs. The analysis indicated that the PHC work has operated without recognizing the residents' needs. Overcoming such gaps may be possible if and to the extent that work processes are implemented according to the recognition of health needs, respecting the concept of determination in the health-disease process and the right to health as a political gain.
\end{abstract}

Primary Health Care; Health Policy; Health Services
Célia Maria Sivalli Campos 1

Silvana Martins Mishima ${ }^{2}$

\section{Introdução}

O tema das necessidades de saúde tem sido abordado sob diferentes bases teórico-conceituais. Este trabalho tomou como ponto de partida os conceitos e categorias gerais da saúde coletiva. Ou seja, compreendendo que o objeto das práticas em saúde coletiva é o coletivo, constitutivamente heterogêneo, heterogeneidade determinada pelas suas características sociais e que o processo saúde-doença do coletivo é produto do processo da reprodução da vida social 1 .

Para viver precisa-se antes de tudo satisfazer necessidades 2 , cuja satisfação encontra-se em potência no produto de um processo de trabalho. Assim, há uma consubstancialidade e uma circularidade entre necessidade e o processo de trabalho instaurado para satisfazê-la.

Nessa perspectiva as necessidades não são naturais nem iguais, pois desiguais são a distribuição e o consumo dos produtos do processo de trabalho ${ }^{3}$.

Este estudo buscou um conjunto de referências teóricas, elaboradas a partir da mesma perspectiva filosófica que serviu de base para a construção do campo da saúde coletiva, para estruturar o trajeto da pesquisa nos seus aspectos teórico e metodológico.

Foi assim que partiu de uma certa tipologia de necessidades, qual seja, a abordagem do conceito na sua dimensão abstrata, apresentada sobretudo por Heller 4 e por parte do estudo 
de Mendes-Gonçalves 3; a abordagem do conceito na sua dimensão concreto-operacional, apresentada especialmente por Stotz 5 e ainda uma abordagem que faz a articulação entre as duas dimensões, apresentada por Mendes-Gonçalves 3 .

Necessidades de saúde serão aqui abordadas no âmbito concreto-operacional do conceito, pois este estudo investigou as necessidades de saúde reconhecidas como objeto das práticas numa UBS (unidade básica de saúde).

A dimensão operacional do conceito permite um recorte de necessidades a partir do qual será organizada a produção de serviços de saúde, as necessidades apresentadas por aqueles que organizam a assistência 5 .

Nessa perspectiva, o processo de produção em saúde (articulação social dos diferentes processos de trabalho em saúde) tem como finalidade responder as necessidades sociais, sinônimo de necessidades de manutenção e reprodução do modo de produção 3 , que se reproduz em necessidades de reprodução das classes sociais. Assim, necessidades de saúde são necessidades de reprodução social que, por não serem naturais nem gerais 3 , são necessidades de classes, ou seja, são diferentes nos diferentes grupos sociais, definidos pela sua inserção na divisão social do trabalho que determina os diferentes modos de viver 6 .

Assim, tomar necessidades de saúde como objeto das práticas em saúde implica adotar uma noção de saúde 7 que considere a inserção dos indivíduos em diferentes grupos sociais. Isso significa que o objeto das práticas em saúde é amplo, abrangendo, além da dimensão biológica, as dimensões: cultural, econômica, ecológica, política, comandadas - no modo de produção capitalista - pela dimensão econômica 8 .

No processo de produção de serviços de saúde os processos de trabalho deveriam tomar como finalidade atender as necessidades de saúde dos grupos sociais que constituem um território. Para a saúde coletiva, atender essas necessidades deveria significar tomar o conceito da determinação social do processo saúde-doença para instaurar processos de trabalho que respondessem por elas no âmbito das raízes dos problemas, do determinante, e também no dos resultados, a doença propriamente dita, e encaminhar a política pública de saúde na direção do direito universal.

É bem verdade que a saúde coletiva como campo de saberes e práticas tem que responder a uma rede de necessidades que podem es- tar em conflito, que vão além das necessidades de saúde da população (necessidades dos trabalhadores, dos gestores, das políticas públicas, dos autores dos programas, dos órgãos financiadores, entre outros).

Tanto que as propostas de atenção à saúde atuais têm convergido para a atenção focal 7,9,10, alimentando o conflito entre a efetivação do direito à saúde e a garantia de um mínimo necessário para a sobrevivência de grupos específicos 9, "em um cenário em que os arranjos entre o setor público e o setor privado nem sempre são pautados em uma racionalidade ética inclusiva, onde a miserabilidade e as situações denominadas de vulnerabilidade social definem o objeto privilegiado das políticas sociais" 10 (p. 3).

Desta forma, a partir da ótica conformada neste estudo, tomar o conceito de necessidades em saúde como operacional para conformar a atenção em saúde coletiva, “alicerçado no entendimento de que as necessidades de saúde são decorrentes das formas como os grupos se inserem na reprodução social" 11 (p. 622), não deveria significar o desrespeito à concepção da determinação do processo saúde-doença, nem o desrespeito à saúde como direito, conquista política legitimada pela Constituição Federal de 1988 e operacionalizada no SUS.

A finalidade deste estudo foi contribuir com a ampliação do conhecimento das necessidades de saúde, oferecendo subsídios para a sua incorporação no recorte do objeto da ação em saúde. Tomou como objetivos: identificar e analisar o que os moradores da área de abrangência de uma UBS reconhecem como necessidades de saúde; identificar e analisar o que os trabalhadores dessa UBS tomam por objeto, na instauração dos processos de trabalho.

\section{Procedimentos metodológicos}

Trata-se de pesquisa qualitativa, nos moldes de um estudo de caso, realizada numa UBS do Município de São Paulo. O projeto de investigação foi apresentado aos gerentes das Unidades de Saúde da Coordenadoria de Saúde do Butantã, localizada no extremo oeste do município, tendo sido indicada a UBS Vila Dalva para a realização da pesquisa.

Utilizou-se entrevista semi-estruturada para a coleta dos dados, com trabalhadores da UBS e com moradores da área de abrangência dessa UBS, num total de 25 entrevistas (roteiro no final do texto). 
Foram entrevistados 11 trabalhadores, um de cada categoria que prestava assistência direta há pelo menos um ano na unidade. Nas categorias com mais de um trabalhador sorteouse o entrevistado.

Foram eleitos 14 moradores do território, participantes de outras instituições ou organizações da sociedade civil localizadas na área de abrangência da UBS, utilizando-se a técnica em cadeias (snowball) 12: um entrevistado indicou outro, até que se montou a amostra da pesquisa. Esses moradores eram representantes das seguintes instituições ou organizações da sociedade civil: uma ONG (que trabalha com o tema da inclusão digital), duas organizações de voluntariado (geração de renda para jovens e manutenção da ordem no bairro), três organizações institucionais (associação e conselho de duas escolas e conselho gestor da UBS), quatro organizações autônomas (centro comunitário da favela, grêmio estudantil e duas sociedades amigos de bairro) e quatro organizações religiosas (duas católicas, uma evangélica e um centro de umbanda).

As questões norteadoras das entrevistas versaram sobre: o que consideravam necessário para que todos os moradores do bairro tivessem saúde; a diferença e como se reconhecia a diferença entre estar com saúde e não estar com saúde; os principais problemas de saúde dos moradores do território; as causas desses problemas; o enfrentamento desses problemas pelos moradores; a contribuição da UBS no aprimoramento das condições de saúde dos moradores; limitações da UBS no aprimoramento das condições de saúde desses moradores. As entrevistas dos trabalhadores da UBS também versavam sobre a forma como eram reconhecidas as necessidades de saúde da população e quais os recursos empregados na UBS para respondê-las.

As entrevistas foram realizadas de fevereiro a maio de 2003, todas gravadas, transcritas e conferidas com a gravação oral.

No processo de análise utilizou-se o método da análise temática 13 , do qual apreendeuse as categorias empíricas: necessidade da presença do Estado, necessidades de reprodução social, necessidade de participação política.

Para o desenvolvimento da pesquisa foram seguidos os procedimentos éticos previstos na Resolução 196 do Conselho Nacional de Ética em Pesquisa.

\section{Necessidades de saúde pela voz dos moradores e dos trabalhadores de saúde}

Os depoimentos reiteraram que as necessidades de saúde são necessidades de reprodução social, tendo sido apreendidas várias ordens de necessidades. Porém, as atinentes à presença precária do Estado no bairro foram tão marcantes nos depoimentos dos moradores, que nos obrigaram a destacá-las. Relacionados a essa precariedade detectou-se relatos de organização da população, tanto para executar atividades que minimizassem os efeitos dessa precariedade quanto a necessidade de participação política dos moradores.

\section{Necessidade da presença do Estado}

Os moradores atribuíram ao Estado a responsabilidade pela garantia de diversos serviços que provêm o bem estar social. Evidenciou-se também um descrédito nas instituições públicas, tanto na garantia do acesso quanto à efetividade dos serviços; foi declarado que conta com o setor público somente quem não tem outra possibilidade de escolha.

Apesar do descrédito nas instituições públicas, a quase totalidade dos representantes dos moradores arrolou serviços públicos como referência para o atendimento dos problemas de saúde; referência essa justificada pelo fato de ser o único recurso existente no bairro e não pela efetividade do atendimento.

Para os moradores a UBS é referência para atender doenças e as ações mais citadas foram as campanhas indicadas pelo Ministério da Saúde (MS). Também entre os trabalhadores de saúde as ações da UBS mais citadas foram as consultas médicas e os programas determinados pelo MS. Ou seja, intervenções que tomam o coletivo como grupo portador de necessidades homogêneas, pois as campanhas prescindem das características dos moradores para a sua formulação.

\section{Necessidades de reprodução social}

Os moradores atribuíram ao Estado a responsabilidade pelos diversos serviços necessários para a reprodução da vida social, a começar pelo saneamento básico. Citaram também a ausência do Estado no seu papel fundamental de responder à necessidade de inserção no mercado formal de trabalho. A sociedade civil sente-se responsabilizada por suprir as carências que ameaçam a sobrevivência dos moradores. 
Já os depoimentos dos trabalhadores da UBS identificaram-se mais com uma narrativa abstrata da vida dos moradores. Ou seja, não está colocado na finalidade do trabalho da UBS o conhecimento sistematizado dos grupos sociais do território de abrangência da UBS.

Grande parte dos representantes dos moradores associou saúde à possibilidade de viver e transformar a vida e doença à dificuldade ou ao impedimento na realização de atividades produtivas para a manutenção da vida. A quase totalidade desses depoimentos atestou que o que determina os agravos à saúde dos moradores do bairro são as suas condições de vida, atribuindo peso determinante às diferenças sociais dos moradores desse território e colocaram o trabalho na base da determinação da saúde.

Compreendendo-se o processo saúde-doença como o embate entre os potenciais de fortalecimento e desgaste advindos dos perfis de reprodução social, observou-se que os diferentes agravos que acometem os moradores do bairro guardam coerência com a inserção na reprodução social característica dos diferentes setores censitários do território.

Assim, representantes dos moradores de plena inserção social citaram agravos à saúde associados ao processo natural de envelhecimento. Quanto aos demais entrevistados, os problemas respiratórios e a verminose foram os agravos mais citados entre as crianças e entre os adultos os mais citados foram alcoolismo com relato de aumento de incidência entre as mulheres - e violência.

A inserção na reprodução social foi unanimemente descrita pelos moradores como o determinante da violência. A vinculação dos jovens no tráfico de substâncias psicoativas foi atribuída à falta de perspectiva de inserção desses jovens no mercado de trabalho, o que impossibilita o acesso ao consumo de mercadorias que os alçam à condição de pertencimento a um determinado grupo, o dos jovens ou o dos socialmente incluídos.

\section{Necessidade de participação política}

Identificou-se que a organização da sociedade civil foi uma tentativa de minimizar precariedades dos moradores e que a participação é mais evidente nos espaços onde os serviços públicos não atendem as necessidades da população, mas também foram implementadas atividades que potencializam a participação política, como a criação do Conselho Gestor na UBS, mesmo que decorrente da exigência da legislação para repasse de recursos federais para a implantação do Programa Saúde da Família.
Na UBS Vila Dalva o Conselho Gestor é uma instância opinativa, sem caráter decisório; é um espaço formal de participação popular, legitimador das práticas da unidade. Foi assinalada pelos moradores a necessidade da ampliação da participação política - tanto dos trabalhadores quanto dos moradores - para além da participação formal no Conselho Gestor, foi sugerido que os trabalhadores da UBS não legitimassem a ausência do Estado e que suas práticas fossem instrumentalizadoras da crítica dos moradores do território.

\section{Discussão}

Os resultados mostraram que a concepção de Estado dos moradores é próxima à concepção do Estado de Bem-estar Social, que garante benefícios sociais e que intervem na relação capital-trabalho 14.

Pode-se dizer que o Brasil nem chegou a constituir-se como Estado de Bem-estar Social. À época em que este já se encontrava em avançado processo de transição para o modelo neoliberal nos países em que se constituiu solidamente, o Brasil passava pela transição democrática que foi consolidada com a promulgação da nova Constituição Federal em 1988, que garantiu a saúde como direito universal e dever do Estado 15.

Porém, se por um lado no Brasil a década de 1980 foi marcada pela Constituição cuja proposição era ampliar os direitos sociais, com fortes traços do Estado de Bem-estar Social, na década seguinte - após instituir-se o direito universal à saúde - teve início um processo de desrespeito a esse direito 16 , com a implantação da lógica neoliberal, seguindo - ainda que mais tardiamente - os países de capitalismo central, nos quais já tinha lugar o ajuste estrutural da economia e o Estado Mínimo, regulador de mercados e fiscalizador da conduta dos agentes econômicos. Para cumprir essa meta os Estados foram pressionados pelos organismos internacionais financiadores a viabilizar as privatizações e as novas modalidades de organização de caráter público-privado. Essa proposta determinou uma redefinição dos espaços institucionais geridos pelo poder público 17 .

O Estado vem diminuindo sua dimensão pública "pela mercantilização de suas políticas e das relações sociais como efeito daquelas" 18 (p. 139). A internacionalização da economia e a desregulamentação estatal têm definido programas econômicos identificados com os objetivos liberais do Fundo Monetário Internacional, do Banco Mundial e da Organização Mundial do Comércio 18. 
Além do ajuste estrutural, através da política econômica, para a consolidação do neoliberalismo é imprescindível uma política social de contenção dos gastos públicos, com um Estado que "só deve intervir com o intuito de garantir um mínimo para aliviar a pobreza e produzir serviços que os privados não podem ou não querem produzir ..." 14 (p. 163).

A opção do Estado brasileiro por essa restrição acarretou tanto a exclusão das camadas que puderam negociar os planos privados de atenção à saúde - os trabalhadores do mercado formal - quanto a focalização social do programa público de saúde para os demais 16 .

Alguns autores consideram que o grande êxito do neoliberalismo tem sido alcançado no âmbito social, político e ideológico, o que não ocorreu no âmbito econômico 19,20. Em que pese seus opositores, a ideologia do neoliberalismo tornou-se então senso comum, uma vez que são as relações de produção que exercem o papel determinante, em última instância, da dinâmica da superestrutura (Direito, Estado, Ideologias) 21. Assim, foram as relações de exploração capitalista norteadas pelo projeto neoliberal que passaram a balizar e induzir a aplicação do Direito, a medida da presença do Estado e as ideologias que garantiriam a adesão ao projeto.

Esse sucesso ideológico e cultural do neoliberalismo manifesta-se em quatro dimensões 20. A primeira delas refere-se "a avassaladora tendência à mercantilização de direitos e prerrogativas conquistadas pelas classes populares (...) convertidos agora em 'bens' ou 'serviços' adquiríveis no mercado. A saúde, a educação e a seguridade social, por exemplo, deixaram de ser componentes inalienáveis dos direitos de cidadão e se transformaram em simples mercadorias intercambiadas entre 'fornecedores' e compradores à margem de toda estipulação políti$c a " 20$ (p. 9).

Essa avaliação crítica é consonante com os depoimentos dos moradores da Vila Dalva, que assinalaram a ausência do Estado na garantia do ensino e da atenção à saúde com qualidade e também a piora dos serviços, conseqüência da crescente privatização desses setores. Uma segunda dimensão diz respeito ao "deslocamento do equilíbrio entre mercados e estado, (...) fenômeno objetivo (...) reforçado (...) no terreno ideológico que 'satanizou' o estado (...). Potentes definições culturais [foram] solidamente arraigadas na população, [associando] o estatal com o mau e o ineficiente e os mercados com o bom e o eficiente" 20 (p. 10).

Reiterando essa afirmação, depoimentos de moradores entrevistados mostraram que so- mente recorre ao setor público quem não pode pagar pelos serviços privados. A terceira dimensão, por sua vez, decorre da "criação de um 'senso comum' neoliberal, (...) que penetra muito profundamente no chão das crenças populares (...). Este conformismo também se exprime no terreno mais elaborado das teorias econômica e sociais, [o chamado] pensamento único" 20 (p. 10).

Consonante com essa terceira dimensão na qual o neoliberalismo se consolida, encontrouse nos depoimentos de representantes de moradores de espaços de plena inserção social do território a constatação da ausência do Estado na garantia do acesso aos direitos que deveriam ser universais, ausência compreendida pelos depoentes como natural, uma vez que acreditam que a ação do Estado deve incidir sobre os pobres, numa clara identificação com a concepção de focalização das políticas sociais do modelo neoliberal. Por último, a quarta dimensão diz respeito ao "convencimento" de “(...) amplissimos setores das sociedades capitalistas - e a quase totalidade de suas elites politicas - de que não existe outra alternativa (...) [e rejeita todo discurso] que se atreva a dizer que a sociedade pode se organizar de outra maneira" 20 (p. 10-1).

Coerentes com esse encaminhamento de lógica neoliberal, os trabalhadores da UBS atribuíram ao Estado a responsabilidade pela implementação de ações voltadas aos pobres.

É possível que tenham essa visão porque, na condição de representantes do Estado, são legitimadores da política pública, estão numa encruzilhada entre a legitimação deste Estado, que favorece o mercado, e a impossibilidade de deixar de ler a realidade dos moradores, o que os coloca numa posição de impotência e inoperância frente à proteção social presente no texto da Constituição Federal.

A população sente e verbaliza claramente esse afastamento do Estado, enquanto o discurso dos trabalhadores é dúbio, porque estão numa posição dúbia, estão numa instituição representativa de um Estado que não é protetor, embora tenha um discurso de proteção social, e que culpabiliza os trabalhadores pela ineficiência dos serviços, embora tenha operacionalizado manobras de satanização das instituições públicas.

Os dados mostraram como esse contexto, que ocasiona o esgarçamento do tecido social, vem conformando a dinâmica da vida das pessoas que ocupam o território de abrangência da UBS, a partir da sua inserção na reprodução social, marcada pela falta de garantia de acesso a direitos, característica da periferização conformada no processo de urbanização da cidade de São Paulo, onde é muito evidente a sepa- 
ração das classes sociais na conformação do espaço urbano.

A ocupação das bordas da cidade, a periferia, pelos pobres é tomada como natural, mas ela não é um fenômeno natural, ela foi forjada no seio da desigualdade, ela é produto do que Sposati 22 (p. 92) denominou "urbanismo da apartação", que determina aos que são empurrados para as franjas da cidade a sobrevivência "em espaços que não são cidade", marcados "pela falta de planejamento, pela inexistente presença do Estado”. O que deu início à periferização já foi a ausência de um Estado legitimador dos direitos sociais, situação que foi se agudizando cada vez mais com a globalização da economia.

O desemprego evidenciado pelos entrevistados é alto e o acesso a alguma atividade para prover necessidades de sobrevivência é difícil, por isso é alto o número de famílias que sobrevivem da caridade.

Esse quadro de precarização no perfil de reprodução social de grande parte dos moradores do bairro é o mesmo que descreveu Sader 18, ao apontar que as conseqüências da relação entre capital e trabalho na contemporaneidade são a terceirização, o trabalho precário, o trabalho doméstico, o trabalho infantil e a remuneração da força de trabalho abaixo de seu valor.

A compensação desse déficit nas atribuições do Estado tem sido feita por um lado através da organização da sociedade civil em grupos que se constituem como instituições, para a realização de ações que tentam fazer as vezes de instituições do Estado, e por outro lado através da compra dos serviços na iniciativa privada. À medida que os governos de orientação neoliberal imprimem a diminuição dos encargos sociais, vão automaticamente transferindo a responsabilidade "às instâncias locais, ao mercado e à sociedade" (Carvalho MCAA. Participação Social no Brasil Hoje. http: / /www.polis.org.br/publicações / papers / 1998.2.html, acessado em 10/Dez/2004).

Grande parte das 14 instituições da sociedade civil da área de abrangência da UBS constituiu-se a partir da mobilização da sociedade civil para responder problemas da população, como por exemplo a instituição criada para suprir o déficit de vagas na educação pública e o da inserção no mercado de trabalho dos jovens que, naquele território, foram ficando à margem das agências de socialização e aderindo a práticas ilegais. Foi também descrita a organização e o desenvolvimento de atividade de cuidados domiciliares à saúde por instituição da sociedade civil, pela ausência de resposta dos serviços públicos de saúde a essa necessidade.
Ainda no âmbito da saúde uma das instituições implementou ações de atenção básica em saúde para jovens - prevenção de gravidez e de doenças sexualmente transmissíveis, cursos para prevenção de acidentes domésticos, entre outras atividades de âmbito intersetorial, para suprir a inoperância da UBS no aprimoramento das condições de saúde dos moradores.

Trata-se da reinvenção do Estado, de que este "se concentre na formulação e na avaliação de políticas públicas e não em sua implementação", que deve ficar a cargo de "organizações não-governamentais ou empresas, de forma descentralizada" 17 (p. 53).

Essas ações têm sido então executadas pelos próprios demandatários, o que tem representado uma mudança radical no paradigma da ação social coletiva 23 . Essa atuação não se estrutura como movimento social, a execução das ações passa a ser articulada em grupos organizados, a partir de projetos, propostas de soluções, estratégias de execução das ações demandadas e o poder público passa a ser o "agente repassador de recursos" 23 (p. 315).

Na área de abrangência da UBS os grupos que se organizaram não se configuram como movimentos sociais, a participação social dessa população tem sido muito menos a participação política nas decisões e muito mais a participação emanada do vácuo criado pela insuficiência dos serviços públicos em responder suas necessidades.

Como conseqüência do rearranjo do Estado, que o tornou mínimo na implementação de políticas sociais, a década de 1990 foi frutífera para a multiplicação e fortalecimento das organizações não governamentais e de parcerias “implementadas pelo poder público, particularmente no âmbito do poder local" 23 (p. 309).

Foi nesse contexto que a participação social dos moradores da Vila Dalva tomou a conformação mais centrada em grupos organizados para responder as demandas sociais originárias da retirada do Estado.

Assim, a retirada do Estado da gestão do espaço público foi também definindo o lugar das ações que respondem ao bem estar social. No embate entre o espaço público e o privado, a participação política ficou delimitada e circunscrita ao âmbito privado das organizações e dos grupos organizados, espaços onde primordialmente se desenvolvem ações focalizadas aos pobres.

Comentando a "crise de confiança no Estado e no bem público", que permeia a sociedade civil, Bourdieu 24 (p. 13) explicita como se constitui essa reação, afirmando que "o cidadão, sentindo-se repelido para fora do Estado (que, 
no fundo, não lhe pede nada, além das contribuições materiais obrigatórias, e principalmente não solicita devotamento nem entusiasmo), repele ao Estado, tratando-o como uma potência estrangeira que ele utiliza do melhor modo para os seus interesses". Esse é outro processo que produz o desinteresse na participação política e conseqüentemente diminui a expressão do conflito social.

O material empírico mostrou que o desemprego foi atribuído, em parte, a algum déficit dos indivíduos, não apontando o posicionamento econômico do Estado na determinação do desemprego. Reiteradas vezes moradores entrevistados atribuíram ao jogo de sorte/azar o fato de conseguirem um bom emprego, de conseguirem continuar os estudos, de conseguirem a consulta médica no momento em que precisam.

Bourdieu 24 (p. 16) atribuiu essa culpabilização e esse mal estar ao que chamou de "retorno ao individualismo", determinado pela concepção que destruiu "a noção de responsabilidade coletiva nos acidentes de trabalho, na doença ou na miséria. (...) O retorno ao indivíduo é também o que permite 'acusar a vítima', unica responsável por sua infelicidade, e the pregar a 'auto-ajuda' (...)".

Esse mecanismo atribui à "sorte [e à] decisão individual o volume dos resultados individuais e coletivos" obtidos. Ou seja, na atualidade em que "o bem-estar é identificado com o consumo, cada indivíduo tem a possibilidade de adquirir os bens que seu próprio esforço lhe permita" 26 (p. 90-1).

Desta forma, os depoimentos dos moradores reiteram a ideologia de responsabilização do indivíduo, que remete para o foro privado a busca pelo emprego e pela satisfação das necessidades de reprodução social, sendo ao indivíduo imputada a competência para perceber e aproveitar as "oportunidades" da sorte.

A "despolitização da sociedade" 9 (p. 113) é um outro mecanismo que leva à privatização da esfera pública. Através do processo de descrença na ação política, as decisões do que deverá ser acatado por todos passam a ser feitas no espaço privado, no âmbito das decisões não consensuais, tomadas por técnicos que legitimarão o projeto do Estado.

Também a educação tem sido utilizada para reiterar a ideologia de responsabilização do indivíduo, como mecanismo de despolitização. $\mathrm{O}$ acesso a ela tem sido utilizado como artifício para justificar "a existência de desigualdades sociais", quando o que ocorre "é um problema matemático" 26 (p. 14), há um número de vagas de empregos que é muito menor do que o de pessoas que precisam ocupá-las. Portanto, a qualificação resolverá o problema individual na concorrência pela mesma vaga, mas nem resvala no problema que é de todos e que está na raiz das desigualdades sociais 26 .

Em relação à outra instituição social do Estado, a UBS, foi-lhe atribuída a falta de efetividade. A avaliação dos moradores é que a instituição não tem sido efetiva para aprimorar as condições de saúde dos moradores do território, nem para permitir acesso da população aos serviços de saúde.

No entanto a legislação do sistema de saúde brasileiro, baseada na Constituição Federal (Artigo 198), enuncia que a saúde é um direito social entre outros, é um direto de todos e ao Estado cabe garanti-lo através de políticas públicas e do "acesso universal e igualitário às ações e serviços para sua promoção e recuperação".

Essa aparente incoerência entre a legislação do SUS e a prática realizada pela UBS pode ser compreendida em Calipo 9 (p. 125), quando afirma que para operacionalizar essa diminuição do Estado, "na área da saúde a reforma do Estado vem se dando com a implantação da Norma Operacional Básica de 1996, a lei que cria as Organizações Sociais e o Programa de Publicização, e a regulamentação dos planos de saúde. Os dois primeiros mecanismos introduzem mudanças na assistência à saúde executada pelo Estado, e a regulamentação dos planos de saúde normatiza os serviços oferecidos pela iniciativa privada".

Assim, constata-se 9,10 a restrição da assistência à saúde aos pobres, especialmente aos grupos de risco, em situação de "vulnerabilidade social" 10 (p. 3) limitando os serviços a umas poucas ações para alguns.

Desta forma fica estabelecida a assistência à saúde na UBS Vila Dalva, que toma os moradores como portadores de necessidades naturalmente homogêneas, pois são estratificados a partir da mesma precariedade na inserção social. Coerente a isso, torna-se indiferente apropriar-se ou não das características de vida dos moradores para a implementação das atividades.

\section{Considerações finais}

Os moradores reconhecem como necessidades de saúde: necessidade da presença do Estado, necessidades de reprodução social e necessidade de participação política. Atribuíram ao Estado a responsabilidade pela garantia dos diversos serviços que promovem o bem estar social, bem como a responsabilidade de interpor- 
se e regular as relações entre capital e trabalho, favorecendo uma reprodução societal regida pelo direito de cidadania.

Para alçar a cidadania os moradores elegeram primordialmente a inserção no trabalho que lhes garanta, para além da sobrevivência, a dignidade, a criatividade e a sociabilidade - e a ampliação da esfera pública, para que as políticas sociais possam ser implementadas a partir da participação política dos cidadãos. Essa participação deve permitir o embate dos interesses dos diferentes setores da sociedade, conformando um projeto emancipatório que oponha resistência ao posicionamento do Estado, de privilégio dos interesses do capital.

Os trabalhadores da UBS tomam por objeto do trabalho os sintomas e as doenças de moradores que conformam a demanda espontânea da unidade, primordialmente constituída por aqueles que não conseguem acessar o mercado privado de atenção à saúde.

\section{Resumo}

Este estudo tomou como objeto as necessidades de saúde de moradores da área de abrangência de uma unidade básica de saúde (UBS) no Município de São Paulo, Brasil. O objetivo geral foi investigar as necessidades de saúde reconhecidas como objeto do trabalho em saúde. Para isso identificou e analisou o que os moradores reconhecem como necessidades de saúde, bem como o que os trabalhadores da UBS tomam por objeto do trabalho. Trabalhadores da UBS e moradores da área de abrangência dessa UBS foram os sujeitos da pesquisa. Utilizou-se a entrevista semi-estruturada para a coleta dos dados e a análise temática para a apreensão da realidade. As categorias empíricas apreendidas foram: necessidade da presença do Estado, necessidades de reprodução social, necessidade de participação política, reconhecidas pelos moradores do território como necessidades de saúde. A análise indicou que os processos de trabalho da UBS têm prescindido do reconhecimento das necessidades dos moradores. A superação dessas reduções será viável quando os processos de trabalho forem instaurados a partir do reconhecimento das necessidades de saúde, respeitando a concepção da determinação do processo saúde-doença e a conquista política do direito à saúde.

Cuidados Primários de Saúde; Política de Saúde; Serviços de Saúde
As necessidades de reprodução social de fato se configuraram nos dados empíricos como necessidades específicas (distintas) dos diferentes grupos sociais, constituindo-se em diagnóstico próprio da estrutura do modo de produção. Já as necessidades da presença do Estado e de participação política encontram-se no campo superestrutural, do exercício pela defesa do direito.

A partir deste estudo coloca-se um desafio a ser tomado pela área de saúde coletiva, o de superar o recorte operacional das necessidades de saúde, invocando também sua dimensão abstrata, como foi apontado por Stotz 5 . Da perspectiva marxista essa aproximação permitiria superar a leitura de necessidades de reprodução do modo de produção, para a leitura de necessidades propriamente humanas e de necessidades radicais 4 , ou seja, do livre exercício da criatividade humana.

\section{Colaboradores}

C. M. S. Campos elaborou a pesquisa que deu origem ao artigo e redigiu o artigo. S. M. Mishima colaborou na elaboração do artigo. 


\section{Referências}

1. Laurell AC. A saúde-doença como processo social. In: Nunes ED, organizador. Medicina social: aspectos históricos e teóricos. São Paulo: Global; 1983. p. 133-58.

2. Marx K, Engels F. A ideologia alemã: I - Feuerbach. 9ạ Ed. São Paulo: Editora Hucitec; 1993.

3. Mendes-Gonçalves RB. Práticas de saúde: processos de trabalho e necessidades. São Paulo: Secretaria Municipal da Saúde de São Paulo; 1992. (Cadernos CEFOR, Série Textos 1).

4. Heller A. Teoria de las necesidades em Marx. 2a Ed. Barcelona: Peninsola; 1986.

5. Stotz EN. Necessidades de saúde: mediações de um conceito (contribuição das Ciências Sociais para a fundamentação teórico-metodológica de conceitos operacionais da área de Planejamento em Saúde [Tese de Doutorado]. Rio de Janeiro: Escola Nacional de Saúde Pública, Fundação Oswaldo Cruz; 1991.

6. Queiroz VM, Salum MJL. Operacionalizando o conceito de coletivo na releitura da categoria da reprodução social. São Paulo: Escola de Enfermagem, Universidade de São Paulo; 1997.

7. Stotz EN. Os desafios para o SUS e a educação popular. http://www.redepopsaude.com.br (acessado em 24/Mai/2004).

8. Samaja J. A reprodução social e a saúde. Salvador: Casa da Qualidade; 2000.

9. Calipo SM. Saúde, Estado e ética - NOB/96 e Lei das organizações sociais: a privatização da instituição pública na saúde? [Dissertação de Mestrado]. São Paulo: Escola de Enfermagem, Universidade de São Paulo; 2002.

10. Nogueira VMR, Pires DEP. Direito à saúde: um convite à reflexão. Cad Saúde Pública 2004; 20: 753-60.

11. Campos CMS, Soares CB. A produção de serviços de saúde mental: a concepção de trabalhadores. Ciênc Saúde Coletiva 2003; 8:621-8.

12. Becker HS. Métodos de pesquisa em ciências sociais. 4a Ed. São Paulo: Editora Hucitec; 1999.

13. Bardin L. Análise de conteúdo. Lisboa: Edições 70; 2000 .
14. Laurell AC. Avançando em direção ao passado. In: Laurell AC, organizadora. Estado e políticas sociais no neoliberalismo. 2a Ed. São Paulo: Cortez; 1997. p. 151-78.

15. Cohn A. Mudanças econômicas e políticas de saúde no Brasil. In: Laurell AC, organizadora. Estado e políticas sociais no neoliberalismo. 2a Ed. São Paulo: Cortez; 1997. p. 225-44.

16. Stotz EN. Trabalhadores, direito à saúde e ordem social no Brasil. São Paulo Perspec 2003; 17:25-33.

17. Moretto A, Pochmann M. A estratégia paulistana de inclusão social. In: Pochmann M, organizador. Desenvolvimento, trabalho e solidariedade: novos caminhos para a inclusão social. São Paulo: Fundação Perseu Abramo; 2002. p. 21-69.

18. Sader E. A vingança da história. São Paulo: Boitempo; 2003.

19. Anderson P. Balanço do neoliberalismo. In: Sader E, Gentili P, organizadores. Pós-neoliberalismo: as políticas sociais e o Estado democrático. 5a Ed. Rio de Janeiro: Paz e Terra; 2000. p. 9-23.

20. Boron AA. Os "novos Leviatãs" e a pólis democrática: neoliberalismo, decomposição estatal e decadência da democracia na América Latina. In: Sader E, Gentili P, organizadores. Pós-neoliberalismo II: que Estado para que democracia? Petrópolis: Editora Vozes; 1999. p. 7-67.

21. Althusser L. Sobre a reprodução. Rio de Janeiro: Editora Vozes; 1999

22. Sposati A. A cidade em pedaços. São Paulo: Brasiliense; 2001

23. Gohn MG. Teorias dos movimentos sociais: paradigmas clássicos e contemporâneos. 3ạ Ed. São Paulo: Loyola; 2002.

24. Bourdieu P. Contrafogos: táticas para enfrentar a invasão neoliberal. Rio de Janeiro: Jorge Zahar Editores; 1998.

25. Bianchetti RG. Modelo neoliberal e políticas educacionais. São Paulo: Cortez; 1997.

26. Bock SD. Trabalho: a inserção do jovem no mercado de trabalho. In: Abramo HW, Freitas MV, Sposito MP, organizadoras. Juventude em debate. São Paulo: Cortez; 2000. p. 11-6.

Recebido em 12/Abr/2004

Versão final reapresentada em 10/Fev/2005

Aprovado em 14/Fev/2005 